\title{
Quality of life in patients treated with radiofrequency ablation for thyroid nodules
}

Silvia Oddo ${ }^{1 *}$, Edineia Felix ${ }^{1}$, Anna Maria Repetto ${ }^{2}$, Michele Mussap $^{2}$ and Massimo Giusti ${ }^{1}$

*Correspondence: dottoressaoddo@gmail.com

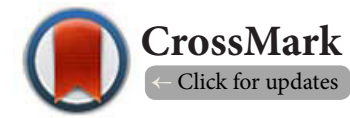

'Endocrinology Unit of IRCSS AOU San Martino University-IST, Genoa, Italy.

${ }^{2}$ Laboratory Medicine Service of IRCSS AOU San Martino University-IST, Genoa, Italy.

\begin{abstract}
Background: Many studies have reported mean reductions in nodule volumes and described improvements in the sense of pressure and aesthetic symptoms after radiofrequency ablation. The aim of our study was to document changes in quality of life by means of a 13-scale questionnaire named ThyPRO in a cohort of patients treated with radiofrequency ablation for benign thyroid nodules. Moreover, we assessed the efficacy and safety of the procedure and correlations between efficacy and some features both of the treated nodules and of patients, and evaluated improvements in neck discomfort by means of a visual analogic scale.

Methods: 32 patients with benign thyroid nodules were treated with radiofrequency ablation. We evaluated nodule volume, thyroid function and autoimmunity before and after procedures, adverse events during and after procedures, changes in neck discomfort by means of a visual analogic scale and changes in quality of life through the ThyPRO questionnaire at 1, 3, 6 12, 24 and 36 months. We sought correlations between response to radiofrequency ablation and some features of procedures and patients. We divided patients into 2 groups, according to their mean percentage of nodule volume reduction: group 1 (reduction $>30 \%$ ) and group 2 (reduction $<30 \%$ ) to evaluate whether ThyPRO questionnaire scores changed in patients in whom thyroid RFA was more effective.

Results: At the last evaluation, nodule volume reduction was $45 \pm 9$ in group 1, $11 \pm 9$ in group 2 and $40 \pm 25 \%$ in the total population. We found a correlation between better volume reduction and greater patient age. Thyroid function and autoimmunity were not modified. Adverse events were few and mild. Visual analogic scale scores improved, though scores on the individual ThyPRO scales did not change, even in group 1. The general subjective impact of thyroid disease on quality of life improved from the 3rd month onwards.

Conclusions: In our cohort of patients, quality of life, as evaluated through ThyPRO, did not improve after radiofrequency for benign thyroid nodules. In the literature, changes in quality of life in patients treated with radiofrequency ablation for thyroid nodules have been described in only one paper, while changes in quality of life assessed by means of ThyPRO have never been described.
\end{abstract}

Keywords: Quality of life, radiofrequency ablation, benign thyroid nodules, thyroid

\section{Background}

The greater availability of diagnostic techniques, together with an increase in attention to thyroid diseases, has led to a significant rise in diagnoses of thyroid cancer [1]. Consquently, the number of thyroidectomies for malignant disease is destined to grow. It is therefore essential to use minimally invasive techniques, such as thyroid radiofrequency ablation (RFA), in order to reduce the number of surgical procedures for benign diseases.
Percutaneous thyroid RFA procedures are less expensive than thyroidectomy, whether total or partial, do not require hospitalization and cause only mild and rare adverse events. Moreover, they can be undertaken in patients with contraindications for surgery due to comorbidities.

Since 2010, the AACE-AME-ETA guidelines have recommended thyroid RFA as a possible therapeutic option for the treatment of benign thyroid nodules [2]. Indications for RFA in 
thyroid nodules are: symptomatic benign disease (discomfort or pain in the neck, dysphagia, foreign body sensation, coughing or discomfort), aesthetic problems or autonomous functioning nodules [3]. Thyroid RFA can also be used to treat autonomous nodules if radiometabolic therapy is refused or not practicable [2]. For cystic nodules, mini-invasive therapy is considered in the case of regrowth after percutaneous ethanol ablation [3].

While many studies have reported reductions in treated nodules and improvements in the sense of pressure and aesthetic symptoms [4], only one study has described changes in quality of life (QoL).

The aim of our study was to evaluate QoL changes in a cohort of patients treated with RFA for benign thyroid nodules from 2012 to 2015 in our department. QoL was monitored by means of a 13-scale questionnaire validated for thyroid diseases, namely Thyroid-specific Patient Reported Outcome (ThyPRO) [5]. Moreover, we assessed the efficacy of the procedure in correlation with certain features of the treated nodules and of patients, and recorded the frequency of adverse events and improvement in neck discomfort.

\section{Materials and methods Subjects}

From January 2012 to March 2015, patients with a benign thyroid nodule or a single predominant benign thyroid nodule (>30 mm in diameter) in the context of a multi-nodular goitre were evaluated in our department with a view to undergoing percutaneous thyroid RFA. These patients had either refused total or subtotal thyroidectomy or had comorbidities that contraindicated surgery. All patients signed an informed consent form that included a detailed explanation of the procedure and its purpose. The study was performed in compliance with the Helsinki Declaration and was approved by University of Genoa Ethics Committee.

From January 2012 to March 2014, we enrolled 32 patients ( 24 females and 8 males) aged between 36 and 80 years (mean $56 \pm 14$ years) with a single thyroid nodule or a predominant thyroid nodule ( $>30 \mathrm{~mm}$ in diameter) in a multi-nodular goitre; 11 patients (34\%) had a single nodule, while 21 (66\%) had a prevalent nodule ( $>30 \mathrm{~mm}$ in diameter) in the context of a goitre. These nodules, which had been discovered $9 \pm 11$ years earlier, were located in the right lobe in 13 patients $(41 \%)$, in the left lobe in 18 patients (56\%) and in the isthmus in 1 patient (3\%). Two patients had undergone ethanol ablation of the nodule approximately one year earlier, without significant benefit. One patient had undergone radioiodine therapy, without apparent benefit. Seven patients were on L-T4 replacement therapy for hypothyroidism at a mean dose of $329 \pm 156 \mathrm{mcg} /$ week. Another patient was taking methimazole ( $2.5 \mathrm{mg} /$ day) for a pre-toxic goitre, which displayed no hot areas on scintigraphy.

After retrospective subdivision of patients into two groups ( $n=16$ each group), no differences were observed in terms of sex, age, BMI, time since diagnosis, functional status of thyroid, nodule volume on enrolment, Joules administered during thyroid RFA, symptomatic visual analogic scale (VAS) (Table 1) or ThyPRO score (Table 2).

Table 1. Data on group 1 and 2 patients.

\begin{tabular}{|c|c|c|c|}
\hline & Group 1 & Group 2 & P-value \\
\hline Males/Females & $03 / 13$ & $05 / 11$ & 0.6 \\
\hline Age (years; mean $\pm S D$ ) & $60 \pm 12$ & $52 \pm 14$ & 0.71 \\
\hline $\mathrm{BMI}\left(\mathrm{kg} / \mathrm{m}^{2} ;\right.$ mean $\left.\pm \mathrm{SD}\right)$ & $25 \pm 3$ & $27 \pm 5$ & 0.95 \\
\hline $\begin{array}{l}\text { Time since diagnosis } \\
\text { (years; mean } \pm \text { SD) }\end{array}$ & $13 \pm 13$ & $7 \pm 8$ & 0.64 \\
\hline VAS score $($ mean \pm SD) & $3 \pm 3$ & $3 \pm 3$ & 1 \\
\hline MNG/UNG & $12 / 04$ & $10 / 06$ & 0.74 \\
\hline Location (right/left) & $09 / 07$ & $10 / 06$ & 0.87 \\
\hline TSH $(\mathrm{mIU} / \mathrm{L} ;$ mean $\pm \mathrm{SD})$ & $1.55 \pm 1.13$ & $1.24 \pm 0.85$ & 0.63 \\
\hline $\begin{array}{l}\text { Nodule volume at baseline } \\
(\mathrm{ml} ; \text { mean } \pm \mathrm{SD})\end{array}$ & $19 \pm 10$ & $26 \pm 16$ & 0.89 \\
\hline $\begin{array}{l}\text { Joules administered } \\
(\mathrm{J} / \mathrm{ml} ; \text { mean } \pm \mathrm{SD})\end{array}$ & $1819 \pm 712$ & $1346 \pm 767$ & 0.72 \\
\hline Follow-up (months; mean \pm SD) & $15 \pm 11$ & $14 \pm 9$ & 0.85 \\
\hline Volume reduction (\%) & $45 \pm 9$ & $11 \pm 17$ & $P<0.0001$ \\
\hline
\end{tabular}

NS= Not significant; MNG: ZMultinodular goitre;

UNG: Uninodular goitre

\section{Protocol}

To perform thyroid RFA, we followed the indications of the Consensus Statement of the Korean Society of Thyroid Radiology [3]. Before procedures, patients underwent complete anamnesis and physical examination, routine blood tests and thyroid function tests (f-T3, f-T4, TSH), evaluation of thyroid autoimmunity, calcitonin and thyroglobulin, ECG and phoniatric examination.

The volume $(\mathrm{ml})$ of the nodule undergoing thyroid RFA was evaluated by means of the ellipsoid formula: antero-posterior diameter $x$ latero-lateral diameter $x$ cranio-caudal diameter $x 0.52 / 1000$. This formula was also used to calculate the total volume of each thyroid lobe [6].

Before thyroid RFA, patients underwent FNAB cytology on the nodule on two separate occasions, to confirm benignity (Thy 2 in accordance with the British Thyroid Association [7]). Only patients with a finding of benignity on both occasions underwent thyroid RFA. Patients filled out both a VAS that rated neck discomfort and a 13-scale Thyroid-specific Patient Reported Outcome (ThyPRO) QoL questionnaire validated for patients with thyroid disease [5].

Clinical examinations, assessments of thyroid function and thyroid autoimmunity and VAS evaluation were repeated after 1 week and 1, 3 and 6 months, and then annually. ThyPRO and ultrasound thyroid volume were evaluated after 1, 3 and 6 months, and then annually. Phoniatric examination was repeated if symptoms related to chordal dysmotility appeared after the procedure.

Subsequently, according to the percentage reduction of the 
Oddo et al. Research Journal of Endocrinology and Metabolism 2016, http://www.hoajonline.com/journals/pdf/2053-3640-4-1.pdf

doi: $10.7243 / 2053-3640-4-1$

Table 2. ThyPRO scores at baseline in groups 1 , in group 2 and total patients (mean $\pm S D)$. Significant $P$ scores are in italic form.

\begin{tabular}{l|lll|lll|lcl}
\hline & \multicolumn{3}{c}{ Total patients } & \multicolumn{3}{c|}{ Group 1 } & \multicolumn{2}{c}{ Group 2 } \\
\cline { 2 - 10 } & Baseline & $\begin{array}{l}\text { Last } \\
\text { Evaluation }\end{array}$ & P-value & Baseline & $\begin{array}{l}\text { Last } \\
\text { Evaluation }\end{array}$ & P-value & Baseline & $\begin{array}{l}\text { Last } \\
\text { Evaluation }\end{array}$ \\
\hline Goiter symptoms & $16 \pm 15$ & $18 \pm 13$ & 0.87 & $16 \pm 16$ & $18 \pm 2$ & 0.71 & $17 \pm 15$ & $14 \pm 12$ & 0.6 \\
Hyperthyroidism symptoms & $13 \pm 13$ & $10 \pm 9$ & 0.74 & $11 \pm 13$ & $10 \pm 7$ & 0.87 & $14 \pm 13$ & $11 \pm 14$ & 0.94 \\
Hypothyroidism symptoms & $15 \pm 14$ & $19 \pm 10$ & 0.71 & $15 \pm 13$ & $19 \pm 0$ & 0.68 & $16 \pm 15$ & $17 \pm 19$ & 0.85 \\
Eye symptoms & $7 \pm 8$ & $19 \pm 22$ & 0.09 & $8 \pm 9$ & $19 \pm 16$ & 0.19 & $7 \pm 7$ & $6 \pm 7$ & 0.88 \\
Tiredness & $33 \pm 17$ & $25 \pm 10$ & 0.53 & $28 \pm 17$ & $25 \pm 7$ & 0.69 & $34 \pm 17$ & $32 \pm 14$ & 0.6 \\
Cognitive problems & $12 \pm 18$ & $13 \pm 12$ & 0.96 & $15 \pm 22$ & $13 \pm 9$ & 0.9 & $9 \pm 8$ & $8 \pm 9$ & 0.84 \\
Anxiety & $19 \pm 18$ & $25 \pm 35$ & 0,66 & $13 \pm 12$ & $25 \pm 25$ & 0.19 & $24 \pm 21$ & $20 \pm 16$ & 0.64 \\
Depressivity & $26 \pm 18$ & $24 \pm 8$ & 0,95 & $23 \pm 17$ & $24 \pm 6$ & 0.97 & $28 \pm 18$ & $20 \pm 18$ & 0.37 \\
Emotional susceptibility & $22 \pm 17$ & $24 \pm 18$ & 0,9 & $20 \pm 17$ & $24 \pm 13$ & 0.79 & $27 \pm 17$ & $19 \pm 16$ & 0.5 \\
Impaired social life & $8 \pm 13$ & $16 \pm 22$ & 0,44 & $5 \pm 9$ & $16 \pm 16$ & 0.2 & $11 \pm 15$ & $5 \pm 8$ & 0.45 \\
Impairmed daily life & $9 \pm 13$ & $17 \pm 23$ & 0,44 & $8 \pm 12$ & $17 \pm 17$ & 0.41 & $10 \pm 14$ & $7 \pm 11$ & 0.63 \\
Impaired sexlife & $9 \pm 20$ & $32 \pm 26$ & 0,14 & $7 \pm 21$ & $32 \pm 19$ & 0.15 & $12 \pm 19$ & $8 \pm 11$ & 0.66 \\
Cosmetic complaints & $10 \pm 13$ & $11 \pm 15$ & 0,95 & $8 \pm 13$ & $11 \pm 11$ & 0.78 & $12 \pm 13$ & $4 \pm 7$ \\
General score & $29 \pm 7$ & $0 \pm 0$ & 0 & $26 \pm 27$ & $0 \pm 0$ & 0.02 & $25 \pm 26$ & $13 \pm 21$ \\
Mean values & $16 \pm 2$ & $19 \pm 6$ & 0,72 & $14 \pm 11$ & $19 \pm 11$ & 0.7 & $17 \pm 12$ & $13 \pm 11$ & 0.19 \\
\hline
\end{tabular}

treated nodule at the last evaluation, patients were divided into two groups: those with $\geq 30 \%$ reduction (group 1 ) and those with $<30 \%$ reduction (group 2). We looked for possible correlations between the degree of nodule reduction and some parameters: baseline volume nodule, Joules administered during thyroid RFA, time since diagnosis, hormonal status (TSH, $\mathrm{f}-\mathrm{T} 3, \mathrm{f}-\mathrm{T} 4$, thyroglobulin on enrolment and 1 week after the procedure) and patient age. The value of $30 \%$ was chosen in accordance with the mean percentage of nodule volume reduction recorded in our centre.

\section{Procedures}

Procedures were carried out in a day-hospital regimen. Antiplatelet and anticoagulant therapies were suspended for an appropriate time before the procedure. On the day of the procedure, patients were in a fasting state. After placement of a venous catheter, patients underwent intravenous infusion of ketorolac $(20 \mathrm{mg})$ and ranitidine $(50 \mathrm{mg})$ diluted in $100 \mathrm{ml}$ of $0.9 \%$ saline solution for 30 minutes. Subsequently, intravenous ketorolac $(40 \mathrm{mg})$ and ranitidine $(50 \mathrm{mg})$ were administered in $500 \mathrm{ml}$ of $0.9 \%$ saline for about 5 hours (during and after thyroid RFA). In subjects allergic to ketorolac or in patients with moderate-to-severe renal impairment, premedication with intravenous paracetamol $(500 \mathrm{mg})$ was carried out before and during the procedure. After thyroid RFA, a compressive bandage and ice were applied to the neck. Patients were allowed a light meal before being discharged in the early afternoon. All subjects received a domiciliary prescription for steroid administration (prednisone $25 \mathrm{mg}$ for 3 days, $12.5 \mathrm{mg}$ for 3 days, 6.25 for 3 days) and gastric protection, if not already ongoing.

\section{Methods}

Thyroid RFA was performed by means of $7 \mathrm{~cm}, 18$ Gauge electrodes with a $1 \mathrm{~cm}$ active tip (Starmed, Seoul, Korea). Procedures were performed with the support of an ultrasound echo-Laser XVG (Esaote, Genoa, Italy) with a 7.5 MHz linear probe (LA523).

Follow-up ultrasound examinations were performed by means of a MyLab Five (Esaote, Genoa, Italy) ultrasound scanner with a $7.5 \mathrm{MHz}$ linear probe (LA523) (Esaote, Genoa, Italy). The radiofrequency generator used was an RF System Viva VRS01 (Starmed, Seoul, Korea). The peristaltic pump was an R4S100 (Starmed, Seoul, Korea).

Thyroid RFA was performed in a single session by a single operator with 3 years' experience by means of a moving-shot technique and trans-isthmic access.

\section{Laboratory tests}

$\mathrm{TSH}, \mathrm{f}-\mathrm{T} 3$ and $\mathrm{f}-\mathrm{T} 4$ were measured by means of ultra-sensitive chemiluminescence immunoassay (Cobas ${ }^{\circ}$ e602, Roche Diagnostics, Milan, Italy). The normal ranges are: $0.27-4.2 \mathrm{mIU} / \mathrm{L}$ for TSH, and 2.76-7.07 pmol/L and 11.97-21.88 pmol/L for $\mathrm{f}-\mathrm{T} 3$ and $\mathrm{f}-\mathrm{T} 4$, respectively. TPOAb and $\mathrm{TgAb}$ were evaluated by means of DiaSorin (Saluggia, Italy), concentrations $<100 \mathrm{mU} / \mathrm{L}$ being regarded as negative. Calcitonin was measured by chemiluminescence immunoassay (DiaSorin); in our laboratory the normal value is $<10 \mathrm{ng} / \mathrm{L}$. Automated complete blood counts were taken by an ADVIA 2120 automated counter (Siemens Healthcare, Milan, Italy); coagulation tests were performed by means of an automated BCS analyzer (Siemens Healthcare, Milan, Italy), and biochemical tests for the routine assessment of hepatic and renal function on the fully-automated Cobas c701 platform (Roche Diagnostics, Milan, Italy). 
Oddo et al. Research Journal of Endocrinology and Metabolism 2016,

http://www.hoajonline.com/journals/pdf/2053-3640-4-1.pdf

doi: $10.7243 / 2053-3640-4-1$

\section{Questionnaires}

The subjective benefits of thyroid RFA were evaluated several times during the study by means of a VAS questionnaire with a score ranging from 0 (no symptoms/discomfort) to 10 (highest level of symptoms/discomfort).

QoL was assessed before the procedure, after 1, 3 and 6 months and then annually, by means of ThyPRO, a validated questionnaire for thyroid diseases which consists of 13 scales with multiple-choice answers ( $0=$ "none"; $1=$ "slight"; $2=$ "moderate"; $3=$ "severe"; $4=$ "very severe"). The ThyPRO scales concern the following aspects: goitre symptoms, hyperthyroid symptoms, hypothyroid symptoms, eye symptoms, tiredness, cognitive problems, anxiety, depressivity, emotional susceptibility, impaired social life, impaired daily life, impaired sexlife, cosmetic complaints.

We also evaluate a further scale, present in the questionnaire that answer to the question "in the last 4 weeks thyroid disease has had a negative effect on your quality of his life?", that we call "general score". Lastly we consider also the mean values of 13-scales score.

\section{Statistical analysis}

All data were analysed by means of GraphPad Prism for Windows (Version 6.0, GraphPad Software, San Diego, CA, USA). The data are presented as means $\pm S D$, unless otherwise indicated. Continuous data were compared by means of the MannWhitney test, while percentages were compared by means of the Fisher test. Correlations between variables were assessed by means of the Spearman correlation. A $P$ value $<0.05$ was deemed to indicate significance.

\section{Results}

\section{Procedure effects}

Procedures were stopped when all portions of the nodule had been ablated, with particular attention being paid to danger triangle and the nodular capsule. Procedures lasted $7 \pm 3$ minutes on average (range: 2:45-15:00 $\mathrm{min}$ ), with a mean delivery of $1575 \pm 767 \mathrm{~J} / \mathrm{ml}$ (range: $13607-43459 \mathrm{~J} ; 349-3171 \mathrm{~J} / \mathrm{ml}$ ) at a mean power of $42 \pm 5 \mathrm{~W}$ (range: $40-50 \mathrm{~W}$ ). On enrolment, the mean volume of the nodules was $22 \pm 14 \mathrm{ml}$ (range: 7-38 ml) and the total gland volume was $39 \pm 16 \mathrm{ml}$ (range: $14-76 \mathrm{ml}$ ) (Table 3). Table 3 reports the reduction in nodular and thyroid volumes at each time-point of the study. The percentage volumetric reductions in the RFA-treated thyroid nodules and in the thyroid volume were statistically significant at 1 , 3, 6, 12 and 24 months (Table 3).

There was no significant correlation between percentage volume reduction and joules administered during the procedure, baseline nodule volume or years since diagnosis. A significant correlation between better reduction and patient age $(P=0.039 ; r=0.365 ; \mathrm{Cl} 95 \%=0.008-0.639)$ was found (Figure 1 ).

\section{Changes in thyroid parameters}

Parameters of thyroid function at the baseline and at the various
Table 3. Reduction (mean $\pm \mathrm{SD}$ in $\mathrm{ml}$ and \%) of nodule and thyroid with significances.

\begin{tabular}{llllll}
\hline & N & $\begin{array}{l}\text { Nodule } \\
\text { volume } \\
(\mathbf{m l})\end{array}$ & $\begin{array}{l}\text { Nodule } \\
\text { volume }(\%)\end{array}$ & $\begin{array}{l}\text { Thyroid } \\
\text { volume } \\
(\mathbf{m l})\end{array}$ & $\begin{array}{l}\text { Thyroid } \\
\text { volume (\%) }\end{array}$ \\
\hline Baseline & 32 & $22 \pm 14$ & -- & $39 \pm 16$ & -- \\
$1^{\text {st }}$ month & 32 & $18 \pm 11$ & $-18 \pm 18^{\star 6}$ & $34 \pm 15$ & $-10 \pm 18^{\star 3}$ \\
$3^{\text {rd }}$ month & 30 & $16 \pm 10$ & $-27 \pm 21^{\star 6}$ & $31 \pm 15$ & $-16 \pm 21^{\star 6}$ \\
$6^{\text {th }}$ month & 26 & $16 \pm 11$ & $-30 \pm 24^{\star 6}$ & $33 \pm 18$ & $-13 \pm 21^{\star 5}$ \\
$12^{\text {th }}$ month & 22 & $16 \pm 10$ & $-27 \pm 22^{\star 6}$ & $31 \pm 15$ & $-14 \pm 24^{\star 4}$ \\
$24^{\text {th }}$ month & 10 & $17 \pm 11$ & $-26 \pm 24^{\star 1}$ & $31 \pm 14$ & $-17 \pm 19^{\star 6}$ \\
$36^{\text {th }}$ month & 2 & $12 \pm 6$ & $-45 \pm 5^{\star 6}$ & $40 \pm 25$ & $-5 \pm 30^{\star 2}$ \\
\hline
\end{tabular}

$\mathrm{N}=$ Number of patients; ${ }^{\star} 1=\mathrm{P}=0.55 ;{ }^{\star} 2=\mathrm{P}=0.16 ;{ }^{\star} 3=\mathrm{P}=0.0017$; ${ }^{*} 4=\mathrm{P}=0.0012 ;{ }^{*} 5=\mathrm{P}=0.0006 ;{ }^{*} 6=\mathrm{P}<0.0001$

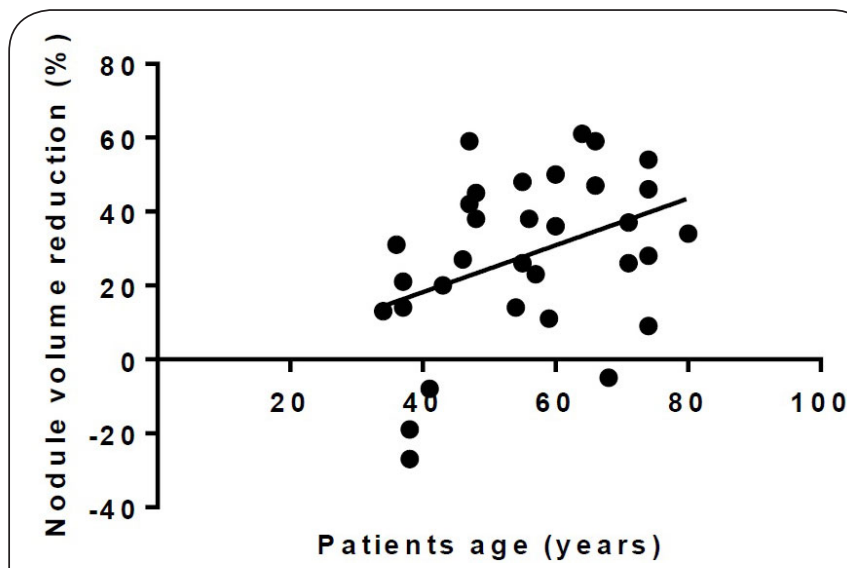

Figure 1. Correlation between nodule reduction (\%) and age of patients.

The $\mathrm{x}$-axis indicates the age of the patients; the $\mathrm{y}$-axis indicates the volume reduction of thyroid nodules. In our study, there was a significant correlation between percentage nodule reduction and patient age: older patients had a greater reduction.

time-points are reported in Table 4. One week after thyroid RFA, F-T4 levels were significantly ( $P=0.02)$ increased, although in the normal range. By the month-1 follow-up examination, they had returned to baseline levels (Table 3). In one case (3\%) $\mathrm{f}-\mathrm{T} 4 \mathrm{increased}$ beyond the normal range, probably owing to iatrogenic destructive thyrotoxicosis, but spontaneously returned to the normal range about 1 month after thyroid RFA. During follow-up, one patient developed overt hypothyroidism, which required L-T4 replacement therapy; this patient had previously displayed TSH and f-T4 values suspicious for overt hypothyroidism. F-T3 and TSH levels did not exhibit significant changes (Table 4). None of the subjects on L-T4 therapy on enrolment had to increase the dosage. Thyroid autoantibody positivity was observed in $28 \%$ of patients $(n=9)$; this percentage was the same at the last evaluation. Thyroglobulin levels were significantly increased 1 week after 
Oddo et al. Research Journal of Endocrinology and Metabolism 2016, http://www.hoajonline.com/journals/pdf/2053-3640-4-1.pdf

Table 4. Changes in thyroid function.

\begin{tabular}{llllll}
\hline & $\mathbf{N}$ & TSH $(\mathbf{m I U} / \mathbf{L})$ & $\mathbf{f}-\mathbf{T 3}(\mathbf{p m o l} / \mathbf{L})$ & $\mathbf{f}-\mathbf{T 4}(\mathbf{p m o l} / \mathbf{L})$ & Thyroglobulin $(\boldsymbol{\mu g} / \mathbf{L})$ \\
\hline Baseline & 32 & $1.4 \pm 0.99$ & $4.88 \pm 0.65$ & $15.4 \pm 2.29$ & $399.15 \pm 778.28$ \\
$1^{\text {st }}$ week & 32 & $1.36 \pm 1.22$ & $4.88 \pm 0.52$ & $17.13 \pm 3.56^{* 1}$ & $1243.70 \pm 2254.49^{* 2}$ \\
$1^{\text {st }}$ month & 32 & $1.27 \pm 0.76$ & $4.82 \pm 0.60$ & $14.80 \pm 3.41$ & $343.82 \pm 779.13$ \\
$3^{\text {rd }}$ month & 30 & $1.26 \pm 0.86$ & $4.96 \pm 0.60$ & $15.70 \pm 2.33$ & $325.06 \pm 686.08$ \\
$6^{\text {th }}$ month & 26 & $1.34 \pm 0.75$ & $4.73 \pm 0.49$ & $14.54 \pm 3.27$ & $494.48 \pm 1114.1$ \\
$12^{\text {th }}$ month & 22 & $1.33 \pm 0.92$ & $4.72 \pm 0.66$ & $15.02 \pm 1.21$ & $280.55 \pm 523$ \\
$24^{\text {th }}$ month & 10 & $1.35 \pm 0.94$ & $4.98 \pm 0.55$ & $14.67 \pm 2.39$ & $297.17 \pm 759.51$ \\
$36^{\text {th }}$ month & 2 & $1.08 \pm 0.5$ & $6.03 \pm 0.28$ & $14.48 \pm 0.09$ & $67 \pm 91.2$ \\
\hline
\end{tabular}

$\mathrm{N}=$ Number of patients; ${ }^{* 1}=\mathrm{P}=0.03 ;{ }^{*}=\mathrm{P}=0.04$

thyroid RFA ( $P=0.049)$ and returned to values comparable to the baseline approximately one month after thyroid RFA $(P=0.77)$ (Table 4). No significant correlation was found between percentage volume reduction and hormonal data $(T S H, f-T 3$, $\mathrm{f}-\mathrm{T} 4$, thyroglobulin on enrolment and after procedure).

\section{Subjective complaints}

During the procedure, 28 patients (88\%) experienced discomfort in the neck, 12 patients (38\%) experienced pain which required a reduction in the voltage of the source of radiofrequency, 4 (13\%) suffered slight haemorrhage from the site of electrode insertion and 1 patient (3\%) had neck oedema. Twelve patients (38\%) did not experience any problems. One week after the procedure, 12 patients (38\%) did not have any problems, $9(28 \%)$ felt discomfort in the neck, $3(9 \%)$ felt pain (mean VAS score: 2), 3 (9\%) had a haematoma, and 1 (3\%) had oedema in the neck. These symptoms did not require any kind of medication and resolved spontaneously during the $1^{\text {st }}$ month. No patient suffered hoarseness, dysphagia, nodule rupture, major bleeding or infections.

The VAS score was $3 \pm 3$ at the baseline; at the last evaluation, it was lower, but not significantly so $(p=0.06)$ (Table 5$)$. Specifically, it decreased significantly from the $1^{\text {st }}$ month to the $6^{\text {th }}$ month after thyroid RFA, but then seemed to worsen at 12, 24 and 36 months (Table 5). In patients with VAS $>0$ on recruitment $(n=23), 74 \%(n=17)$ reported an improvement in

Table 5. Changes in VAS score (mean $\pm \mathrm{SD})$.

\begin{tabular}{lll}
\hline & $\mathbf{N}$ & Score \\
\hline Baseline & 32 & $3 \pm 3$ \\
$1^{\text {st }}$ week & 32 & $2 \pm 2$ \\
$1^{\text {st }}$ month & 32 & $1 \pm 2^{*}$ \\
$3^{\text {rd }}$ month & 30 & $1 \pm 2^{*}$ \\
$6^{\text {th }}$ month & 26 & $1 \pm 2^{*}$ \\
$12^{\text {th }}$ month & 22 & $1 \pm 2$ \\
$24^{\text {th }}$ month & 10 & $3 \pm 2$ \\
$36^{\text {th }}$ month & 2 & $3 \pm 4$ \\
\hline $\mathrm{N}=$ Number of patients; ${ }^{*}=\mathrm{P}=0.02$
\end{tabular}

symptoms, $17 \%(n=3)$ stability of symptoms and $17 \%(n=3)$ worsening of neck symptoms.

The score on each single scale of the ThyPRO questionnaire was unchanged after thyroid RFA (Figure 2). By contrast, the "general scale" of ThyPRO showed a significant improvement in scores $(P=0.02)$ from the baseline to the $3^{\text {rd }}$ month; this QoL improvement persisted over time (Figure 3 ).

Likewise, analysis of the ThyPRO scores of group 1 patients (nodule reduction $>30 \%$ ) revealed that single scores on the 13 scales did not change significantly.

\section{Discussion}

We performed all thyroid RFA procedures according to the consensus statement of the Korean Society of Thyroid Radiology [3]. The duration of thyroid RFA in our hands was much lower than that reported in the literature [8]. This difference can be ascribed to the personal choice of the operator, whose main objective was to prevent severe side effects. Indeed, the appearance of transient hyperechoic zone during thyroid RFA may hinder visualization of the electrode, thus jeopardizing the safety of the procedure. It is therefore not surprising that the mean reduction in nodular volume was slightly lower in our hands than in other centres [4]. However, the reduction in volume remained stable over time, at least up to the $24^{\text {th }}$ month after the procedure, as reported in other studies $[4,9]$.

To our knowledge, there are no data on the relationship between thyroid RFA efficacy and nodule echogenicity or the presence of UNG or MNG; this issue was addressed in our study, but no significant results emerged. Similarly, no study in the literature has analysed the response to thyroid RFA as a factor of patient age, sex, BMI, time since diagnosis, L-T4 therapy and hormonal status; our evaluation did not yield a significant correlation between thyroid RFA efficacy and any of these features, apart from age. Indeed, in our cohort, older patients displayed a better reduction in thyroid nodule volume; we do not know the reason for this finding, but we might hypothesize a different intracellular content in older patients, which could facilitate necrosis after thyroid RFA.

In two of our patients, thyroid RFA was performed approximately one year after percutaneous ethanol ablation. In these 


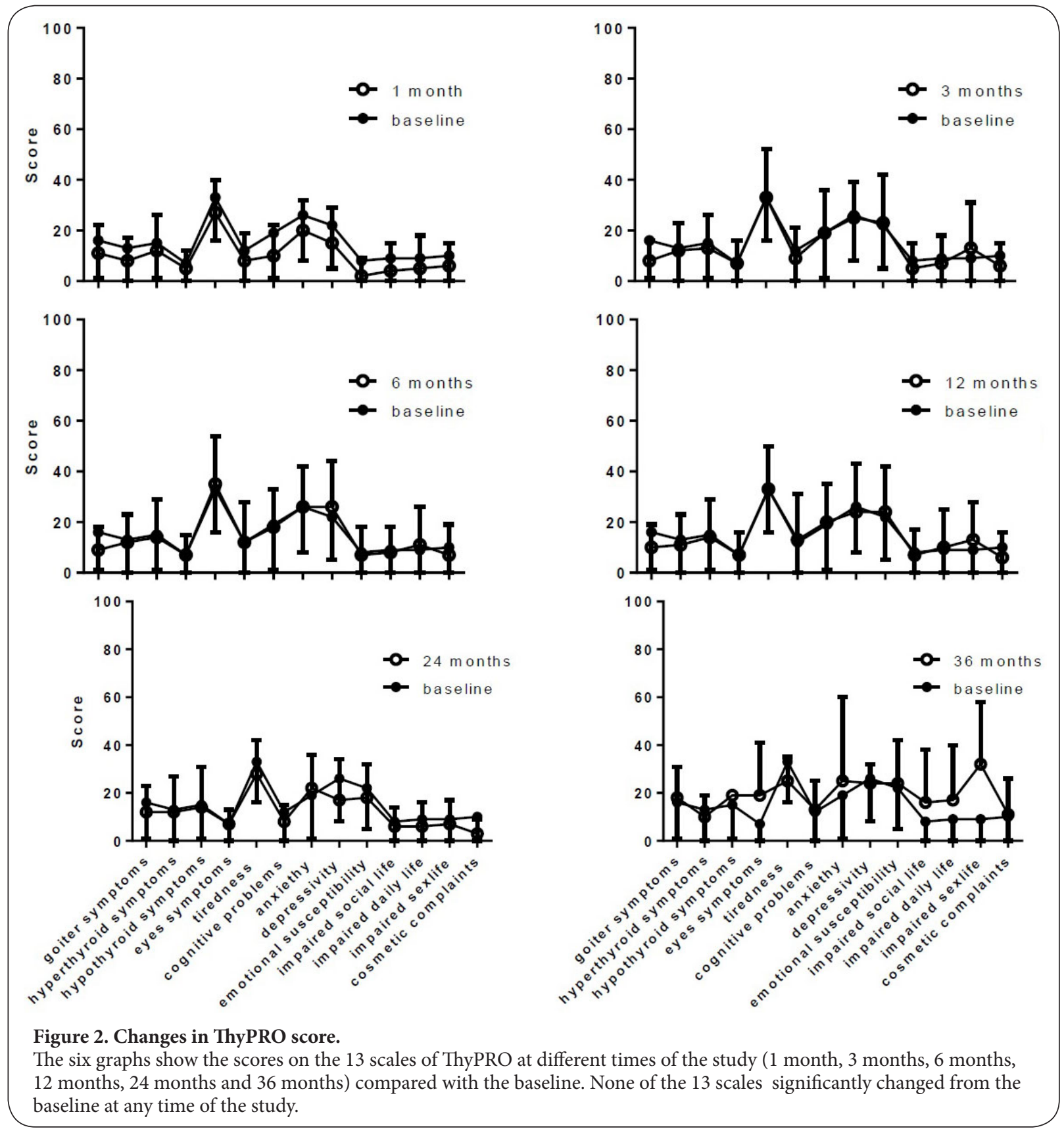

two patients, there was no significant reduction in volume even after thyroid RFA; in a study by Sung et al. (2013), both thyroid RFA and percutaneous ethanol ablation of cystic thyroid nodules seemed to be effective, achieving similar volume reductions [10].

Thyroid RFA-treated patients did not have any serious complications during or after the procedure; no patient reported symptoms or showed signs of complications of severity comparable to those cited in the literature, which reports a percentage of around 3-5\% [11].

In our study, thyroid RFA did not lead to significant changes in thyroid function or thyroid autoimmunity. The levels of thyroglobulin and f-T4 increased significantly a week after the procedure, but returned to their previous values about one month after the treatment. These data have not been reported in any other study.

Many studies have reported improvements in neck discomfort and aesthetic symptoms after thyroid RFA. In the literature, aesthetic issues have been assessed by means of a score (generally from 1 to 4 or from 0 to 3) [12]. In our study, we used The aesthetic scale of ThyPRO, which did not reveal any improvement after thyroid RFA. However, it should be noted that all our patients 


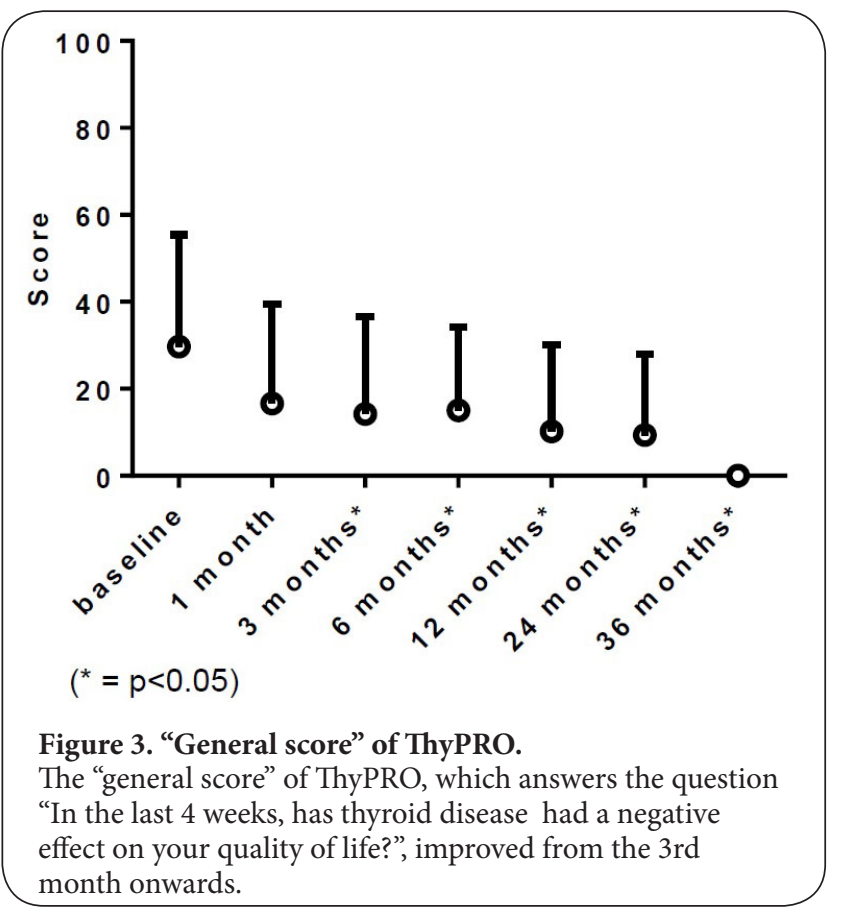

had very low baseline scores on this scale. In many studies, neck discomfort has been evaluated by means of a score (usually from 1 to 4 or from 0 to 3) [3]. Like us, Baek et al. [9] used a $10 \mathrm{~cm}$ VAS analogue scale [9]. A recent study by Valcavi et al. (2015) reported an improvement in VAS from $5.6 \pm 3.1 \mathrm{~cm}$ to $1.9 \pm 1.3$ $\mathrm{cm}$ [14] after 2-year follow-up of benign thyroid nodules treated with thyroid RFA. Our patients displayed a significant improvement in VAS at the $1^{\text {st }}, 3^{\text {rd }}$ and $6^{\text {th }}$ month follow-up examinations; however, the significance seemed to shrink with time. Thus, at 12 months, the improvement in neck discomfort was at the limit of significance; this borderline significance was lost after the $12^{\text {th }}$ month, probably because of the decrease in the number of patients at the subsequent time-points of the study.

QoL is defined as a person's perception of his/her position in life, in the context of the culture and system of values in which he/she lives and in relation to its objectives, expectations, standards and concerns [14].

In the case of thyroid diseases, QoL is often assessed by means of various inventories (e.g. SF-36, Hamilton scale and the Kellner Symptoms Questionnaire). Questionnaires for QoL evaluation have been used in numerous benign and malignant thyroid diseases, such as benign goitre treated with RAI following rhTSH premedication, autoimmune hypothyroidism and chronic autoimmune thyroiditis [14-23]. Only one study has reported changes in QoL in patients treated with RFA for benign thyroid nodules; Valcavi et al. (2015) reported a significant improvement in QoL in 40 patients treated with RFA for benign thyroid nodules, as assessed by means of the Physical Component Summary (from 50.4 \pm 8.9 to $54.5 \pm 5.3$ ) and Mental Component Summary (from $36.0 \pm 13.3$ to $50.3 \pm 6.3$ ) after 2 years of follow-up [13]. This questionnaire consists of 8 scales, 3 of which concern physical health (physical functioning, limitation of specific activities due to physical problems, pain), 2 reflect general health (general health and vitality), and the remaining 3 measure aspects of psychological and emotional health (social activities, limitation of specific activity due to emotional problems, mental health). The Physical Component Summary and Mental Component Summary are two synthetic indexes that summarize the results of the 8 scores in just two numbers: the higher the score, the better the level of health perceived [13].

In our study, none of the scores on the single ThyPRO scales changed significantly from the baseline to the last evaluation. However, the overall score was significantly lower at the month-3 evaluation, and this reduction persisted over time. To our knowledge, no data on QoL evaluated by means of ThyPRO in patients treated with RFA for thyroid nodules have been reported.

Some studies in the literature have evaluated QoL by means of ThyPRO after other therapies for goitre. Fast et al. (2014) found that the majority of patients treated with rhTSH for goitre reported an improvement in symptoms on the specific ThyPRO scale concerning goitre, and that the improvement persisted at least up to the $36^{\text {th }}$ month [19]. Moreover, according to studies conducted by two groups of surgeons on patients who had undergone thyroidectomy for goitre, QoL improved significantly after surgery, whether total thyroidectomy or hemithyroidectomy had been performed $[\mathbf{2 4 , 2 5 ]}$.

\section{Conclusions}

In conclusion, our study shows that thyroid RFA can be effective both in reducing the volume of the nodule and in alleviating neck symptoms. In our study, the efficacy of thyroid RFA correlated with patient age. The procedure proved to be safe; adverse events were few and mild in comparison with surgery or radioiodine therapy. Thyroid RFA was well tolerated by patients and VAS scores improved a few months after the procedure. However, in our cohort of patients, scores on the 13 individual ThyPRO scales did not improve after RFA for benign non-functioning thyroid nodules. By contrast, the "general scale" of ThyPRO, which answers the question "In the last 4 weeks, has thyroid disease had a negative effect on your quality of his life?", showed a significant improvement in scores, and this QoL improvement persisted over time.Further studies will be necessary in order to confirm or contradict our data, especially in a cohort of patients with a better response to thyroid RFA in terms of nodule volume reduction.

\section{List of abbreviations}

RFA: Radiofrequency ablation;

QoL: Quality of life

ThyPRO: Thyroid-specific Patient Reported Outcome

VAS: Visual analogic scale

\section{Competing interests}

The authors declare that they have no competing interests. 
Oddo et al. Research Journal of Endocrinology and Metabolism 2016,

http://www.hoajonline.com/journals/pdf/2053-3640-4-1.pdf

\section{Authors' contributions}

\begin{tabular}{|l|c|c|c|c|c|}
\hline Authors' contributions & SO & EF & AMR & MM & MG \\
\hline Research concept and design & $\checkmark$ & -- & $\checkmark$ & $\checkmark$ & $\checkmark$ \\
\hline Collection and/or assembly of data & $\checkmark$ & $\checkmark$ & -- & -- & $\checkmark$ \\
\hline Data analysis and interpretation & $\checkmark$ & -- & -- & -- & $\checkmark$ \\
\hline Writing the article & $\checkmark$ & -- & -- & -- & $\checkmark$ \\
\hline Critical revision of the article & $\checkmark$ & -- & -- & -- & $\checkmark$ \\
\hline Final approval of article & $\checkmark$ & $\checkmark$ & $\checkmark$ & $\checkmark$ & $\checkmark$ \\
\hline Statistical analysis & $\checkmark$ & -- & -- & -- & $\checkmark$ \\
\hline
\end{tabular}

\section{Acknowledgement}

We thank Dr. Bernard Patrick for revising the English of the manuscript.

\section{Publication history}

Editor: Hamdy Ahmad Sliem, Suez Canal University, Egypt.

Received: 09-Sep-2016 Final Revised: 14-Oct-2016

Accepted: 24-Oct-2016 Published: 01-Nov-2016

\section{References}

1. Shah JP. Thyroid carcinoma: epidemiology, histology and diagnosis. Clin Adv Hematol Oncol. 2015; 13:3-6.

2. Gharib H, Papini E, Paschke R, Duick DS, Valcavi R, Hegedus L and Vitti P. American Association of Clinical Endocrinologists, Associazione Medici Endocrinologi, and European Thyroid Association medical guidelines for clinical practice for the diagnosis and management of thyroid nodules: Executive Summary of recommendations. J Endocrinol Invest. 2010; 33:287-91. | Article | PubMed

3. Na DG, Lee JH, Jung SL, Kim JH, Sung JY, Shin JH, Kim EK, Kim DW, Park JS, Kim KS, Baek SM, Lee Y, Chong S, Sim JS, Huh JY, Bae JI, Kim KT, Han SY, Bae MY, Kim YS and Baek JH. Radiofrequency ablation of benign thyroid nodules and recurrent thyroid cancers: consensus statement and recommendations. Korean J Radiol. 2012; 13:117-25. | Article I PubMed Abstract I PubMed FullText

4. Papini E, Pacella CM, Misischi I, Guglielmi R, Bizzarri G, Dossing $\mathrm{H}$ and Hegedus $L$. The advent of ultrasound-guided ablation techniques in nodular thyroid disease: towards a patient-tailored approach. Best Pract Res Clin Endocrinol Metab. 2014; 28:601-18. | Article | PubMed

5. Watt T, Hegedus L, Groenvold M, Bjorner JB, Rasmussen AK, Bonnema $\mathrm{SJ}$ and Feldt-Rasmussen U. Validity and reliability of the novel thyroidspecific quality of life questionnaire, ThyPRO. Eur J Endocrinol. 2010; 162:161-7. I Article I PubMed

6. Le Moli R, Wesche MF, Tiel-Van Buul MM and Wiersinga WM. Determinants of longterm outcome of radioiodine therapy of sporadic non-toxic goitre. Clin Endocrinol (Oxf). 1999; 50:783-9. I Article I PubMed

7. Agarwal A and Kocjan G. FNAC thyroid reporting categories: value of using the British Thyroid Association (Thy 1 to Thy 5) thyroid FNAC reporting guidelines. Cytopathology. 2009; 20:133-4. | Article I PubMed

8. Gharib H, Hegedus L, Pacella CM, Baek JH and Papini E. Clinical review: Nonsurgical, image-guided, minimally invasive therapy for thyroid nodules. J Clin Endocrinol Metab. 2013; 98:3949-57. I Article I PubMed

9. Baek JH, Kim YS, Lee D, Huh JY and Lee JH. Benign predominantly solid thyroid nodules: prospective study of efficacy of sonographically guided radiofrequency ablation versus control condition. AJR Am J Roentgenol. 2010; 194:1137-42. | Article | PubMed

10. Sung JY, Baek JH, Kim KS, Lee D, Yoo H, Kim JK and Park SH. Singlesession treatment of benign cystic thyroid nodules with ethanol versus radiofrequency ablation: a prospective randomized study. Radiology. 2013; 269:293-300. | Article | PubMed

11. Baek JH, Lee JH, Sung JY, Bae JI, Kim KT, Sim J, Baek SM, Kim YS, Shin JH, Park JS, Kim DW, Kim JH, Kim EK, Jung SL and Na DG. Complications encountered in the treatment of benign thyroid nodules with US-guided radiofrequency ablation: a multicenter study. Radiology. 2012; 262:33542. | Article | PubMed
12. Wong KP and Lang $\mathrm{BH}$. Use of radiofrequency ablation in benign thyroid nodules: a literature review and updates. Int J Endocrinol. 2013; 2013:428363. | Article | PubMed Abstract | PubMed FullText

13. Valcavi R and Tsamatropoulos P. Health-Related Quality of Life after Percutaneous Radiofrequency Ablation of Cold, Solid, Benign Thyroid Nodules: A 2-Year Follow-up Study in 40 Patients. Endocr Pract. 2015; 21:887-96. | Article | PubMed

14. Crevenna R, Zettinig G, Keilani M, Posch M, Schmidinger M, Pirich C, Nuhr M, Wolzt M, Quittan M, Fialka-Moser V and Dudczak R. Quality of life in patients with non-metastatic differentiated thyroid cancer under thyroxine supplementation therapy. Support Care Cancer. 2003; 11:597603. | Article | PubMed

15. Giusti M, Sibilla F, Cappi C, Dellepiane M, Tombesi F, Ceresola E, Augeri C, Rasore $\mathrm{E}$ and Minuto F. A case-controlled study on the quality of life in a cohort of patients with history of differentiated thyroid carcinoma. $J$ Endocrinol Invest. 2005; 28:599-608. I PubMed

16. Giusti M, Melle G, Fenocchio M, Mortara L, Cecoli F, Caorsi V, Ferone $D$, Minuto $F$ and Rasore $E$. Five-year longitudinal evaluation of quality of life in a cohort of patients with differentiated thyroid carcinoma. J Zhejiang Univ Sci B. 2011; 12:163-73. | Article | PubMed Abstract | PubMed FullText

17. Hoftijzer HC, Heemstra KA, Corssmit EP, van der Klaauw AA, Romijn JA and Smit JW. Quality of life in cured patients with differentiated thyroid carcinoma. J Clin Endocrinol Metab. 2008; 93:200-3. | Article | PubMed

18. Tan LG, Nan L, Thumboo J, Sundram F and Tan LK. Health-related quality of life in thyroid cancer survivors. Laryngoscope. 2007; 117:507-10. | Article I PubMed

19. Hirsch D, Ginat M, Levy S, Benbassat C, Weinstein R, Tsvetov G, Singer J, Shraga-Slutzky I, Grozinski-Glasberg S, Mansiterski Y, Shimon I and Reicher-Atir R. Illness perception in patients with differentiated epithelial cell thyroid cancer. Thyroid. 2009; 19:459-65. | Article | PubMed

20. Fast $S$, Hegedus L, Pacini F, Pinchera A, Leung AM, Vaisman M, Reiners C, Wemeau JL, Huysmans DA and Harper W et al. Long-term efficacy of modified-release recombinant human thyrotropin augmented radioiodine therapy for benign multinodular goiter: results from a multicenter, international, randomized, placebo-controlled, dose-selection study. Thyroid. 2014; 24:727-35. | Article | PubMed Abstract | PubMed FullText

21. Watt T, Hegedus L, Bjorner JB, Groenvold M, Bonnema SJ, Rasmussen AK and Feldt-Rasmussen U. Is Thyroid Autoimmunity per se a Determinant of Quality of Life in Patients with Autoimmune Hypothyroidism? Eur Thyroid J. 2012; 1:186-92. | Article | PubMed Abstract | PubMed FullText

22. Giusti M, Caorsi V, Mortara L, Caputo M, Monti E, Schiavo M, Bagnara $\mathrm{MC}$, Minuto $\mathrm{F}$ and Bagnasco $\mathrm{M}$. Long-term outcome after radioiodine therapy with adjuvant rhTSH treatment: comparison between patients with non-toxic and pre-toxic large multinodular goitre. Endocrine. 2014; 45:221-9. | Article | PubMed

23. Winther KH, Watt T, Bjorner JB, Cramon P, Feldt-Rasmussen U, Gluud C, Gram J, Groenvold M, Hegedus L, Knudsen N, Rasmussen AK and Bonnema SJ. The chronic autoimmune thyroiditis quality of life selenium trial (CATALYST): study protocol for a randomized controlled trial. Trials. 2014; 15:115. | Article | PubMed Abstract | PubMed FullText

24. Mishra A, Sabaretnam M, Chand G, Agarwal G, Agarwal A, Verma AK and Mishra SK. Quality of life (QoL) in patients with benign thyroid goiters (pre- and post-thyroidectomy): a prospective study. World J Surg. 2013; 37:2322-9. | Article | PubMed

25. Schmitz-Winnenthal FH, Schimmack S, Lawrence B, Maier U, Heidmann $\mathrm{M}$, Buchler MW and von Frankenberg M. Quality of life is not influenced by the extent of surgery in patients with benign goiter. Langenbecks Arch Surg. 2011; 396:1157-63. | Article | PubMed

Citation:
Oddo S, Felix E, Repetto AM, Mussap M and Giusti M.
Quality of life in patients treated with radiofrequency
ablation for thyroid nodules. Res J Endocrinol Metab.
2016; 4:1. http://dx.doi.org/10.7243/2053-3640-4-1

